\title{
Biological Function of Nuclear Receptor Tyrosine Kinase Action
}

\author{
Sungmin Song ${ }^{1,2,4}$, Kenneth M. Rosen ${ }^{1,3,4}$, and Gabriel Corfas ${ }^{1,2,3}$ \\ ${ }^{1}$ F.M. Kirby Neurobiology Center, Children's Hospital Boston, Massachusetts 02115 \\ ${ }^{2}$ Department of Neurology, Harvard Medical School, Boston, Massachusetts 02115 \\ ${ }^{3}$ Department of Otolaryngology, Harvard Medical School, Boston, Massachusetts 02115 \\ Correspondence: gabriel.corfas@childrens.harvard.edu
}

Receptor tyrosine kinases (RTKs) were believed until recently to act at the cell membrane in a singular fashion (i.e., binding of ligands on the extracellular domain would activate the intrinsic tyrosine kinase activity in the intracellular domain), which would then start a cascade involving other intracellular signaling molecules that would act as effectors. However, new evidence indicates that some RTKs can signal through a different modality; they can move into the nucleus where they directly exert their actions. Although some studies have showed that the proteolytically released intracellular domain of several RTKs can move to the nucleus where they influence gene expression and cell function, others suggest that RTKs can also move to the nucleus as holoproteins. The identification of this novel signaling mechanism calls for a critical reevaluation of the mechanisms of action of RTKs and their biological roles.

$\mathrm{R}^{\mathrm{c}}$ eceptor tyrosine kinases (RTKs) are type I transmembrane proteins that typically transduce signals originating at the cell surface, which then influence numerous cellular processes, in many cases by ultimately impacting on gene expression. For years, it had been believed that RTKs could only signal by what now should be referred to as "canonical RTK signaling" (Fig. 1), a multistep process involving: (1) the binding of their cognate ligands (most frequently growth factors), (2) hetero- or homodimerization of the receptor leading to activation of the intrinsic tyrosine kinase, (3) cytoplasmic domain auto- or transphosphorylation that generates binding sites for intracellular adaptor proteins, and (4) activation of intracellular signaling cascades that impact on the cell's biology (Lemmon and Schlessinger 2010). However, more recent studies have uncovered a novel signaling mechanism used by RTKs (i.e., direct nuclear signaling) (Fig. 2). In this modality, following receptor activation, instead of involving a multicomponent cytoplasmic signaling cascade, the cleaved intracellular domain transits to the nucleus to influence transcription. Some studies have also reported the translocation of full-length RTKs to the nucleus, but whether this actually occurs and whether it has a signaling role is still in debate (Schlessinger and Lemmon 2006). Here we summarize the current

\footnotetext{
${ }^{4}$ These authors contributed equally to this work. Editors: Joseph Schlessinger and Mark A. Lemmon

Additional Perspectives on Signaling by Receptor Tyrosine Kinases available at www.cshperspectives.org

Copyright (C) 2013 Cold Spring Harbor Laboratory Press; all rights reserved; doi: 10.1101/cshperspect.a009001 Cite this article as Cold Spring Harb Perspect Biol 2013;5:a009001
} 
S. Song et al.

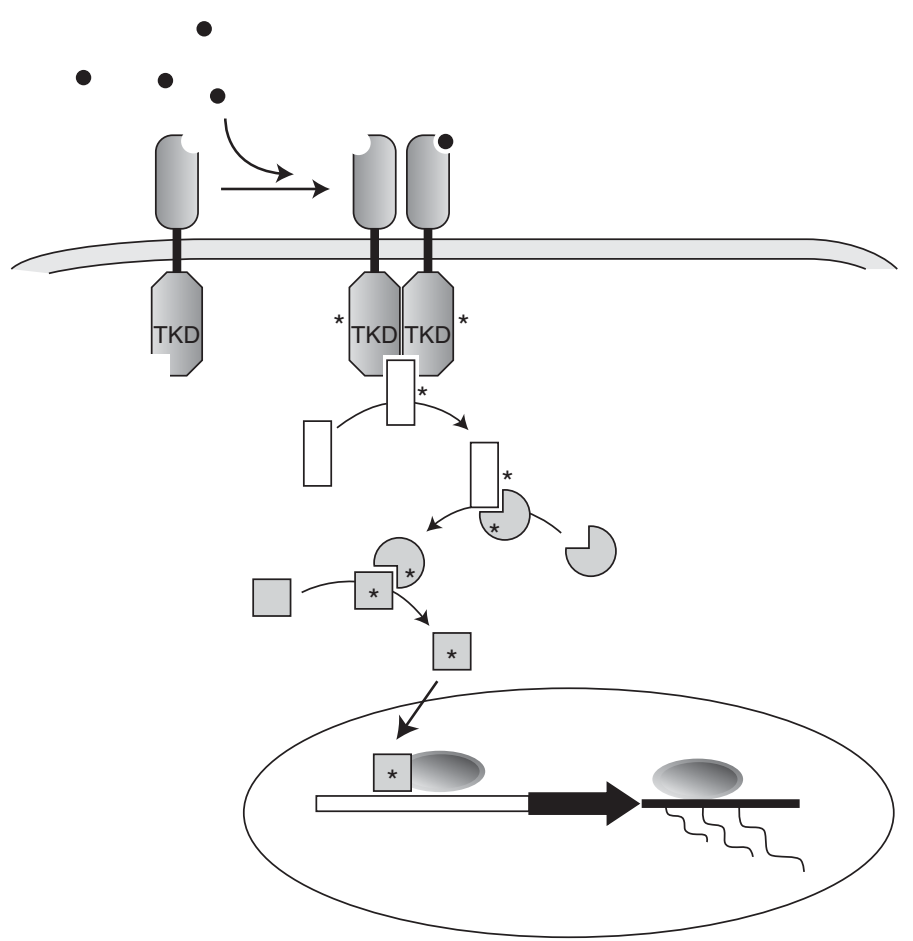

Figure 1. Canonical receptor tyrosine kinase signaling. Activation of a receptor tyrosine kinase at the cell surface leads first to dimerization, followed by activation and phosphorylation of the receptor itself in its intracellular domain. The activated receptor then recruits downstream cytoplasmic signaling molecules, in many cases other kinases. Activation of the downstream signaling cascade frequently leads to changes in gene expression. TKD, tyrosine kinase domain.

understanding of the wide array of mechanisms and biological roles that have been attributed to RTK nuclear signaling, with a particular emphasis on the ErbB receptors, the RTK family for which nuclear signaling has been characterized most extensively.

\section{ErbB4 AND NUCLEAR SIGNALING}

The ErbB4 RTK, as the name implies, was the fourth member of the EGF (or ErbB) receptor family to be identified (Plowman et al. 1993). Alternative splicing in the extracellular juxtamembrane (JM) and cytoplasmic domains of erbB4 generates several isoforms (Elenius et al. 1997, 1999). The splicing in both regions influences the biology of the receptor, but most germane to the discussion here is the variation that occurs in the juxtamembrane region. Two jux- tamembrane isoforms exist, JMa and JMb (Elenius et al. 1997), which result in ErbB4 isoforms that differ in their susceptibility to targeted proteolytic cleavage. Stimulation of ErbB4-JMa by its ligand neuregulin 1 (NRG1) (Zhou and Carpenter 2000) or the activation of protein kinase $\mathrm{C}$ by TPA (12-O-tetradecanoylphorbol13-acetate) (Vecchi et al. 1996; Elenius et al. 1997) promotes cleavage in the extracellular juxtamembrane region, causing the release of a $120-\mathrm{kD}$ ectodomain fragment and leaving behind a transmembrane-tethered $80-\mathrm{kD}$ intracellular domain fragment (mE4ICD). In contrast, ErbB4-JMb is uncleavable (Rio et al. 2000). ErbB4-JMa cleavage can be blocked by TAPI, an inhibitor of tumor necrosis factor- $\gamma$-converting enzyme (TACE), and does not occur in TACE-deficient cells (Rio et al. 2000) linking this metalloprotease (also known as $\alpha$-secretase, 


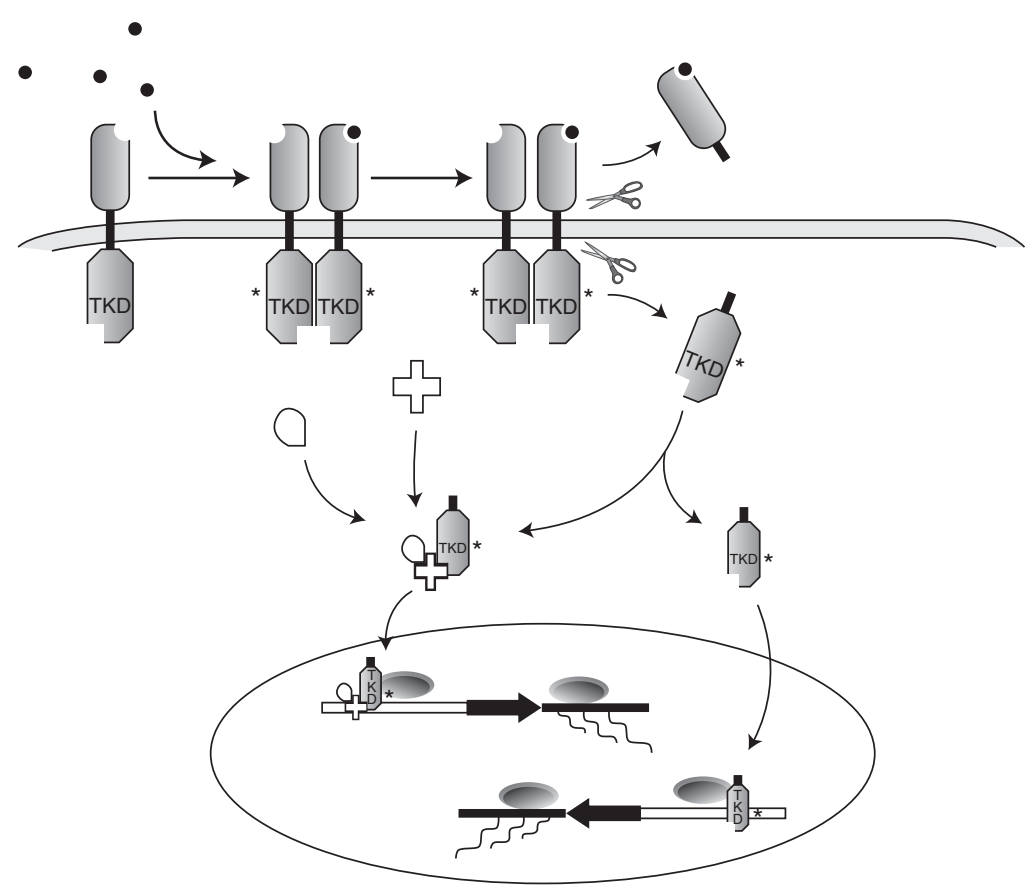

Figure 2. Direct nuclear signaling through a released RTK intracellular domain. Following activation by ligand, specific proteolytic cleavages lead to the release of an activated tyrosine kinase-containing intracellular domain (ICD). Known examples of nuclear signaling by RTK-ICDs include: (a) formation of a cytoplasmic complex containing the ICD and other effector molecules, which then translocates to the nucleus (e.g., ErbB4), and (b) direct nuclear translocation of a released RTK-ICD (e.g., Ryk). Both examples can lead to changes in gene expression.

ADAM17) to the ectodomain shedding of ErbB4. Following this cleavage event, the mE4ICD fragment serves as a substrate for regulated intramembrane proteolysis by the Presenilin-1 (PS1)/ $\boldsymbol{\gamma}$-secretase complex, releasing a soluble intracellular domain (sE4ICD), which has a nuclear localization signal that mediates its import to the nucleus ( $\mathrm{Ni}$ et al. 2001). This adds ErbB4 JMa to a growing list of membrane proteins, including the $\beta$-amyloid precursor protein ( $\beta \mathrm{APP})$ and Notch, that are cleaved sequentially by different secretase enzymes, specifically generating a soluble cytoplasmic domain, which can then enter the nucleus (reviewed by Fortini 2002).

Signaling via ErbB4 has been implicated in a number of both normal and pathological processes in multiple cell types; however, the functional importance of a nuclear-localized E4ICD is only beginning to be fully appreciated. Given that erbB4 is necessary for breast development and lactation (Jones et al. 1999; Long et al. 2003; Tidcombe et al. 2003), and that it is involved in neoplastic breast tissue development (Sundvall et al. 2008), breast-derived tissue and cell lines have served as a rich area for investigation of the role of nuclear ErbB4 signaling. As milk production is a recognized sign of mammary epithelium differentiation, molecular events that regulate the expression of milk components are often viewed as proxies for mammary differentiation. In this context, Williams et al. (2004) found that stimulation of ErbB4 by neuregulin-1 (NRG1) in a breast cancer cell line leads to the association of sE4ICD and STAT5A with the promoter of the $\beta$-casein gene inducing its activity. Another study using breast cancer cells showed that activation of ErbB4 by NRG1 leads to the tyrosine phosphorylation of the largely nuclear localized c-Abl target $\mathrm{Hdm} 2$, and that this phosphorylation is sensitive to both inhibitors of ErbB receptor kinases and of TACE or $\gamma$-secretase, 
S. Song et al.

implying that sE4ICD generation is required (Arasada and Carpenter 2005). A recent study of resected breast tumors showed that the subcellular location of ErbB4 is a critical prognostic indicator, with tumors displaying membranous ErbB4 associated with better clinical outcomes, whereas the presence of nuclear-localized sE4ICD is associated with higher proliferative potential and greater transcription at genes bearing an estrogen response element (ERE) (Junttila et al. 2005). The association between E4ICD and estrogen responsive gene expression has been extended by a study showing that $\mathrm{E} 4 \mathrm{ICD}$ is found along with $\mathrm{ER} \alpha$ at the promoters for the progesterone receptor and SDF-1 genes, whereas the noncleavable mutant ErbB4 V673I fails to coactivate ER $\alpha$-dependent gene transcription (Zhu et al. 2006).

Nuclear ErbB4 signaling has also emerged as an important signaling modality in the nervous system, one of the sites originally identified as expressing the cleavable JMa isoform (Elenius et al. 1997). A study examining oligodendrocytes showed that NRG1-induced changes in the maturation of these cells, including the induction of myelin basic protein expression, are dependent on both $\gamma$-secretase activity and sE4ICD nuclear translocation (Lai and Feng 2004). Sardiet al. (2006) found that, during brain development, ErbB4 nuclear signaling plays a critical role in the process of astrogenesis. This study showed that NRG1-induced ErbB4 activation in neural precursor cells induces the release of sE4ICD, which forms a transcriptional repressor complex with $\mathrm{TAB} 2$ and the nuclear corepressor N-CoR. After nuclear translocation, this complex binds to promoter elements of astrocytic-associated genes, repressing their expression. These data provide a mechanism for the precocious astrogenesis that was observed in mice lacking nervous system ErbB4 expression. More recently, Allison et al. (2011) have shown that NRG1 treatment of cultured hippocampal neurons leads to a dramatic increase in nuclear E4ICD in a presenilin- $1 / \gamma$-secretase-dependent manner. Using global pathway analysis, this study also showed that nuclear sE4ICD signaling has a major effect on the expression of genes important to the morphogenesis of dendritic spines, perhaps lending credence to the suspected involvement of the neuregulin-1/ErbB4 signaling pathway in the pathobiology of schizophrenia.

\section{Ryk, NUCLEAR SIGNALING AND THE Wnt PATHWAY}

The ligands of the Wnt family play critical roles in the establishment of the body map during embryogenesis in all animals (van Amerongen and Nusse 2009). Whereas a great deal is known about the canonical Wnt signaling pathway acting through the Frizzled/LRP receptor complex (Nusse 2005), much less is known about signals that are transduced by selected Wnt family members through the Ryk tyrosine kinase. Recent work has shown that this receptor controls aspects of neuronal differentiation in the developing brain (Lyu et al. 2008). In a manner that parallels the mechanism described above for ErbB4, once Ryk is activated by Wnt, its intracellular domain is released by a $\gamma$-secretase-dependent proteolytic cleavage. During cortical development, Ryk-ICD accumulates in the nucleus where it increases production of neurons from undifferentiated precursor cells. Suitably, the level of Ryk-ICD is highest at the peak of neurogenesis and decays thereafter (Lyu et al. 2008). It is interesting that both ErbB4 and Ryk presenilin-dependent nuclear signaling appear to enhance neurogenesis, the first by restricting astrogenesis, the latter by increasing neuronal differentiation.

\section{TrkA NUCLEAR LOCALIZATION IN THE LIVER}

The tropomyosin-related kinase (Trk A, B, C) family of RTKs is well known for its involvement in the transduction of signals induced by the neurotrophins (NGF, BDNF, NT-3, and NT-4) and for their effects on neuronal survival and differentiation in the developing and mature nervous system (Reichardt 2006). However, it is the liver where nuclear localization of TrkA ICD was observed by Bonacchi et al. (2008). Using immunostaining, this group found nuclear TrkA in hepatic stellate cells of the injured 
liver. Because the signal was detected by antibodies against TrkA's intracellular domain but could not be detected with antibodies directed against its extracellular domain, they concluded that the released ICD was responsible for the labeling. Interestingly, a nuclear signal was also detected using phospho-TrkA-specific antibodies, suggesting that the nuclear TrkA-ICD might be in an active state. The mechanism by which TrkA is cleaved in this context remains to be determined. Previous research identified these same cells in the liver as a source of NGF that is modulated by injury (Cassiman et al. 2001). Together with the observation that NGF induces hepatic cell migration, these findings suggest the possibility that an autocrine loop involving NGF-mediated nuclear TrkA signaling might play a role in the response of the liver to injury (Bonacchi et al. 2008).

\section{NUCLEAR TRANSLOCATION AND FUNCTION OF ErbB2}

ErbB2 was originally identified as a cellular oncogene (Schechter et al. 1984) and has been found to be mutated or overexpressed in many human tumors. Unlike the other members of the ErbB family, ErbB2 remains an orphan receptor with no bona fide ligand. Nevertheless, ErbB2 becomes active in cell surface signaling through heterodimerization with other ErbB family members (Hynes and MacDonald 2009). Whereas nuclear ErbB2 has been detected in many tumors, there is limited information regarding what induces its translocation and what genes it may influence. Using both immunofluorescence and subcellular fractionation techniques, Wang et al. (2004) identified ErbB2 holoreceptor in the nucleus of both tumor tissue and cultured tumor cells and found that it interacts with a sequence in the promoter for the cyclooxygenase- 2 gene, an important modulator of cytokine expression (Fig. 3). This interaction appears to depend on a transactivation domain in the carboxy-terminal cytoplasmic region of the receptor. Regarding how the receptor gains entry to the nucleus, Giri et al. (2005) suggested a mechanism involving a presumptive nuclear localization signal in ErbB2 that mediates inter-
Nuclear Signaling by Receptor Tyrosine Kinases

action with importin $\beta 1$. Similarly, Chen et al. (2005) identified a putative nuclear localization signal in the cytoplasmic domain of ErbB2 and showed that it was sufficient to drive the nuclear entry of a fusion construct created with green fluorescent protein. More recently, Béguelin et al. (2010) have shown that ErbB2, the progesterone receptor (PR), and the transcription factor Stat 3 interact and that together they can regulate the expression of the cyclin D1 gene. Importantly, ErbB2 nuclear translocation depended not only on forming a complex with PR but also required the nuclear localization signal in the cytoplasmic domain of ErbB2. Understandably, the potential that nuclear localized ErbB2 regulates the expression of genes related to tumor progression has been a driving force for studying this process. However, a recent study suggests a potential for a much larger impact of nuclear ErbB2 signaling on cell behavior. Li et al. (2011) reported that nuclear ErbB2 regulates the expression of genes encoding ribosomal RNA by a mechanism involving RNA polymerase-I and that this interaction also affects cell translation and consequently cell size and overall growth, and that these effects occur independently of the canonical downstream activation of PI3 kinase and extracellular signal-regulated kinase (ERK).

\section{FUNCTIONS OF NUCLEAR ErbB3}

As a result of its identification (Kraus et al. 1989), ErbB3 has posed somewhat of a conundrum regarding the mechanism by which it signals. Because of the presence of specific amino acids at key sites in the presumed kinase domain, this RTK has largely been believed to be inactive and only able to function through heterodimerization with other ErbB receptors (Citri et al. 2003), but recent data showed that ErbB3 has tyrosine kinase activity (Shi et al. 2010). Studies of prostate cancer tissue samples as well as cell lines derived from prostate tumors have been a significant resource for characterizing the nuclear localization of ErbB3. A study that analyzed prostate neoplasms of varying pathological grades found that nuclear ErbB3 localization is associated with malignant growths but 
S. Song et al.

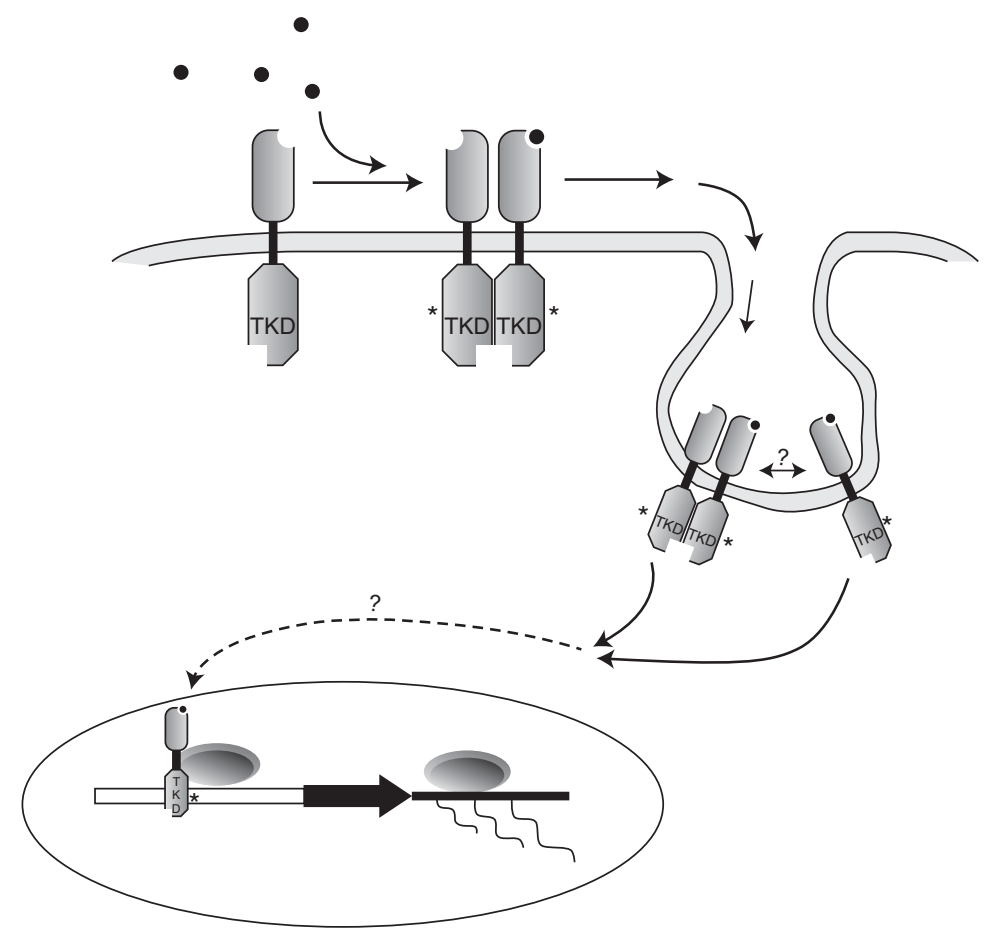

Figure 3. Nuclear signaling by holoreceptor tyrosine kinase. It has been proposed that following activation by its ligand, some intact activated RTKs can be internalized through endocytic or other yet unknown mechanisms, followed by their translocation to the nucleus. It is unknown whether this involves monomer or dimerized RTKs; some reports suggest that ligand-bound RTKs can be found in the nucleus.

not with normal tissue or tissue derived from benign prostatic hypertrophy, and that nuclear expression can also be used to differentiate between hormone-responsive versus nonresponsive growths (Koumakpayi et al. 2006). The implications of these data are that the presence of nuclear ErbB3 is associated with cells that are undergoing abnormally enhanced growth.

The nature of the ErbB3 molecule in the nucleus (holoreceptor vs. ICD) and how it gets there remains unclear. Koumakpayi et al. (2011), reported the presence of full-length ErbB3 holoprotein in the nuclei of prostate cancer cells and that it moves from the cell surface to the nucleus via a nonclathrin-, noncaveolin-dependent endocytic pathway that is sensitive to the effects of amiloride, a macropinocytosis inhibitor. In a line of immortalized, nonmalignant human mammary epithelial cells, Offterdinger et al. (2002) found ErbB3 nuclear localization to be mediated by its $\mathrm{COOH}$ terminus and an apparent nuclear localization signal. Furthermore, the nuclear localization of ErbB3 was enhanced by allowing for the establishment of epithelial cell polarity. Additionally, treatment with NRG1 shifted ErbB3 localization from the nucleus into the nucleoplasm and ultimately into the cytoplasm, suggesting that both the extent of epithelial polarization and activation by NRG1 influence the subcellular localization of this RTK. Recently, Adilakshmi et al. (2011) detected in primary rat Schwann cells a nuclear variant of ErbB3 (nuc-ErbB3) that results from an alternative transcription initiation site. The nuc-ErbB3 isoform contains a functional nuclear localization signal sequence and it binds to chromatin, regulating transcriptional activity from the promoters of the ezrin and HMGB1 genes, and suppression of nucErbB3 expression both reduces myelination and alters the distribution of ezrin in the nodes of Ranvier. 


\section{BIOLOGICAL FUNCTIONS OF NUCLEAR EGF RECEPTOR (ErbB1)}

Numerous studies have reported the localization of the full-length epidermal growth factor receptor (EGFR, ErbB1) in the nucleus, where evidence suggests it can influence transcription, cell proliferation, and DNA repair. Activated nuclear EGFR has been shown to bind to AT-rich response sequences within the promoters of the genes for cyclin D1, B-Myb, iNOS, and Aurora- $A$, and nuclear EGFR has been shown to cooperate with several transcription factors including E2F1 and STAT5, ultimately modifying target gene expression (Lin et al. 2001; Lo et al. 2005; Hanada et al. 2006; Hung et al. 2008). More recently, it has been found that nuclear EGFR can interact with the STAT3 transcription factor to drive the expression of COX-2 in glioblastomas (Lo et al. 2010). Furthermore, nuclear localized EGFR also has been shown to phosphorylate the proliferating cell nuclear antigen (PCNA) at Tyr211, an event that increases its stability (Wang et al. 2006). Thus, nuclear EGFR signaling may contribute to cell proliferation independently of transcriptional regulation.

Exposure of cells to ionizing radiation leads to nuclear translocation of holo-EGFR in a ligand-independent manner, an event associated with an increase in the activity of DNA-dependent protein kinase and enhanced levels of DNA repair (Dittmann et al. 2005). This group also found that the nonsteroidal anti-inflammatory drug celecoxib increases radiosensitization of tumor cells by inhibiting ligand-independent nuclear EGFR transport in response to radiation exposure, and these effects are independent of the inhibitory effects of celecoxib on COX-2 activity as well as modulation of prostaglandin E2 levels (Dittmann et al. 2008). Furthermore, Hsu et al. (2009) showed that nuclear EGFR localization is necessary for tumor resistance to DNA damage caused by the alkylating agent, cisplatin. Whereas the exact molecular mechanisms as to how nuclear EGFR impacts on DNA repair in normal cells are still unclear, nuclear EGFR has been shown to associate with p53 and the MDC1 protein, essential proteins for the recruitment of DNA repair foci (Dittmann et al. 2008). These data suggest that nuclear EGFR may be beneficial for normal cells responding to DNA damage caused by radiation but it might negatively impact tumor-targeting therapies.

\section{VASCULAR ENDOTHELIAL GROWTH FACTOR RECEPTOR 2 (VEGFR2 OR KDR) AND NUCLEAR ACTIVITY}

The regulation of angiogenesis plays a key role throughout the course of development, and inappropriate vascularization is a frequent occurrence in multiple disease states, especially cancer. One of the best known positive modulators of angiogenesis is vascular endothelial growth factor (VEGF), which acts largely through its receptor VEGFR2, making these molecules important targets for cancer treatment (Folkman 2007). Investigation of the responses of endothelial cells to in vitro wounding identified nuclear translocation of an activated VEGFR2/VEGF complex as a key component of the cellular response to injury (Santos et al. 2007). Intriguingly, more recent work has shown that nuclear VEGFR2 may actually play a role in the regulation of expression of the VEGFR2 gene itself. This has been strengthened by the observation that a VEGFR2/Sp1 complex interacts with the VEGFR2 promoter (Domingues et al. 2011).

\section{TYPE I IGF RECEPTOR, POSTTRANSLATIONAL MODIFICATION AND NUCLEAR TRANSLOCATION}

Unlike all other receptors discussed here, the type 1 insulin-like growth factor receptor (IGF$1 \mathrm{R}$ ) is not a single chain type I transmembrane protein. Like the insulin receptor, it exists as a heterodimer containing extracellular ligandbinding $\alpha$ subunits paired with transmembrane dimerized $\beta$ subunits. Signaling via this RTK influences cell growth, size, and maintenance of many cell populations throughout the organism (LeRoith and Roberts 2003). A recent study showed that the complete receptor complex translocates to the nucleus in a manner that is dependent on the posttranslational and activation-dependent addition of the small ubiquitinlike modifier (SUMO) to the kinase-containing 
S. Song et al.

$\beta$-subunit (Sehat et al. 2010). Immunoprecipitation/Western blot analysis showed that, as occurs for many of the RTKs discussed here, the IGF-1R only enters the nucleus after activation, as judged by the presence of phosphorylated tyrosine residues. Using an unbiased approach with synthetic random sequence oligonucleotides in electrophoretic mobility shift assays, followed by assays using chromatin immunoprecipitation, Sehat et al. (2010) also find that the nuclear IGF-1R binds to chromatin and modifies transcriptional activity of many genes.

\section{FIBROBLAST GROWTH FACTOR RECEPTOR 1}

The fibroblast growth factor (FGF) family has many members that signal through four different high-affinity RTKs (FGFR1-4). The ligands also can interact with heparin sulfate, an association that can influence receptor signaling in a wide range of cells and tissues (Harmer 2006). The four FGF RTKs share similar domain structures (i.e., a single transmembrane domain, a split TK domain, and a carboxy-terminal domain). Currently, FGFR1 is the only FGF receptor reported to be present in the nucleus, where it is present in its full-length form and in association with FGF2 (Stachowiak et al. 1996a,b; Myers et al. 2003). Although it remains controversial as to how the ligand reaches the receptor, there is some evidence that this pathway has biological effects on neural precursors. Nuclear FGFR1 signaling has been implicated in the differentiation of neural precursor cells in culture, inducing expression of neuron-specific enolase and Neurofilament-L (Stachowiak et al. 2003) as well as tyrosine hydroxylase (Peng et al. 2002), possibly acting downstream of BMP signaling (Horbinski et al. 2002; Stachowiak et al. 2003). In the subventricular zone (SVZ) of the developing mouse brain, which contains proliferating progenitor cells, FGFR1 immunoreactivity is localized in a predominantly nonnuclear manner, whereas in differentiating cells outside of the SVZ, FGFR1 accumulates in the nuclei (Fang et al. 2005). Consequently, it has been proposed that nuclear FGFR1 signaling is involved in the differentiation of neuronal populations.

\section{CONCLUDING REMARKS}

Whereas early observations of nuclear translocation of RTKs, either as fragments or holoproteins, raised the possibility that RTKs had the ability to signal directly to the nucleus, the mechanism and biological roles for this type of signaling are just now beginning to emerge. As this new arena for RTK action is explored in greater detail, several important questions will need to be addressed: (1) If activated holoreceptors move from the plasma membrane to the nucleus, do they maintain the same conformation? (2) Do different pools of a specific RTK participate in cytoplasmic versus nuclear signaling, or can one molecule perform both? (3) Given the role of $\gamma$-secretase in the release of soluble RTK-ICDs, should their processing and subsequent nuclear signaling be evaluated in the context of Alzheimer's disease? (4) How do nuclear RTKs or RTK-ICDs interact with chromatin and what are their partners and targets? (5) And, of course, what are the biological roles of this new signaling modality? We believe that these studies will provide important insights into the basic mechanisms of cell biology, developmental biology, and disease.

\section{ACKNOWLEDGMENTS}

This work is supported in part by National Institute of Neurological Disorders and Stroke (NINDS) grant R01 NS35884 (to G.C.) and National Institute on Deafness and Other Communication Disorders (NIDCD) grant R01 DC04820 (to G.C.).

\section{REFERENCES}

Adilakshmi T, Ness-Myers J, Madrid-Aliste C, Fiser A Tapinos N. 2011. A nuclear variant of ErbB3 receptor tyrosine kinase regulates ezrin distribution and Schwann cell myelination. J Neurosci 31: 5106-5119.

Allison JG, Das PM, Ma J, Inglis FM, Jones FE. 2011. The ERBB4 intracellular domain (4ICD) regulates NRG1-induced gene expression in hippocampal neurons. Neurosc Res 70: 155-163.

Arasada RR, Carpenter G. 2005. Secretase-dependent tyrosine phosphorylation of $\mathrm{Mdm} 2$ by the ErbB-4 intracellular domain fragment. J Biol Chem 280: 30783-30787.

Beguelin W, Diaz Flaque MC, Proietti CJ, Cayrol F, Rivas MA, Tkach M, Rosemblit C, Tocci JM, Charreau EH, 
Schillaci R, et al. 2010. Progesterone receptor induces ErbB-2 nuclear translocation to promote breast cancer growth via a novel transcriptional effect: ErbB-2 function as a coactivator of Stat3. Mol Cell Biol 30: 5456-5472.

Bonacchi A, Taddei ML, Petrai I, Efsen E, Defranco R, Nosi D, Torcia M, Rosini P, Formigli L, Rombouts K, et al. 2008. Nuclear localization of TRK-A in liver cells. Histol Histopathol 23: 327-340.

Cassiman D, Denef C, Desmet VJ, Roskams T. 2001. Human and rat hepatic stellate cells express neurotrophins and neurotrophin receptors. Hepatology 33: 148-158.

Chen QQ, Chen XY, Jiang YY, Liu J. 2005. Identification of novel nuclear localization signal within the ErbB-2 protein. Cell Res 15: 504-510.

Citri A, Skaria KB, Yarden Y. 2003. The deaf and the dumb: The biology of ErbB-2 and ErbB-3. Exp Cell Res 284: 54-65.

Dittmann K, Mayer C, Fehrenbacher B, Schaller M, Raju U, Milas L, Chen DJ, Kehlbach R, Rodemann HP. 2005. Radiation-induced epidermal growth factor receptor nuclear import is linked to activation of DNA-dependent protein kinase. J Biol Chem 280: 31182-31189.

Dittmann K, Mayer C, Kehlbach R, Rodemann HP. 2008. The radioprotector Bowman-Birk proteinase inhibitor stimulates DNA repair via epidermal growth factor receptor phosphorylation and nuclear transport. Radiother Oncol 86: 375-382.

Domingues I, Rino J, Demmers JA, de Lanerolle P, Santos SC. 2011. VEGFR2 translocates to the nucleus to regulate its own transcription. PLoS ONE 6: e25668.

Elenius K, Corfas G, Paul S, Choi CJ, Rio C, Plowman GD, Klagsbrun M. 1997. A novel juxtamembrane domain isoform of HER4/ErbB4. Isoform-specific tissue distribution and differential processing in response to phorbol ester. J Biol Chem 272: 26761-26768.

Elenius K, Choi CJ, Paul S, Santiestevan E, Nishi E, Klagsbrun M. 1999. Characterization of a naturally occurring ErbB4 isoform that does not bind or activate phosphatidyl inositol 3-kinase. Oncogene 18: 2607-2615.

Fang X, Stachowiak EK, Dunham-Ems SM, Klejbor I, Stachowiak MK. 2005. Control of CREB-binding protein signaling by nuclear fibroblast growth factor receptor-1: A novel mechanism of gene regulation. J Biol Chem 280: 28451-28462.

Folkman J. 2007. Angiogenesis: An organizing principle for drug discovery? Nat Rev Drug Discov 6: 273-286.

Fortini ME. 2002. $\gamma$-Secretase-mediated proteolysis in cellsurface-receptor signalling. Nat Rev Mol Cell Biol 3: 673684.

Giri DK, Ali-Seyed M, Li LY, Lee DF, Ling P, Bartholomeusz G, Wang SC, Hung MC. 2005. Endosomal transport of ErbB-2: Mechanism for nuclear entry of the cell surface receptor. Mol Cell Biol 25: 11005-11018.

Hanada N, Lo HW, Day CP, Pan Y, Nakajima Y, Hung MC. 2006. Co-regulation of B-Myb expression by E2F1 and EGF receptor. Mol Carcinog 45: 10-17.

Harmer NJ. 2006. Insights into the role of heparan sulphate in fibroblast growth factor signalling. Biochem Soc Trans 34: $442-445$.

Horbinski C, Stachowiak EK, Chandrasekaran V, Miuzukoshi E, Higgins D, Stachowiak MK. 2002. Bone mor-
Nuclear Signaling by Receptor Tyrosine Kinases

phogenetic protein-7 stimulates initial dendritic growth in sympathetic neurons through an intracellular fibroblast growth factor signaling pathway. J Neurochem 80: $54-63$.

Hsu SC, Miller SA, Wang Y, Hung MC. 2009. Nuclear EGFR is required for cisplatin resistance and DNA repair. Am J Transl Res 1: 249-258.

Hung LY, Tseng JT, Lee YC, Xia W, Wang YN, Wu ML, Chuang YH, Lai CH, Chang WC. 2008. Nuclear epidermal growth factor receptor (EGFR) interacts with signal transducer and activator of transcription 5 (STAT5) in activating Aurora-A gene expression. Nucleic Acids Res 36: $4337-4351$.

Hynes NE, MacDonald G. 2009. ErbB receptors and signaling pathways in cancer. Curr Opin Cell Biol 21: 177-184.

Jones FE, Welte T, Fu XY, Stern DF. 1999. ErbB4 signaling in the mammary gland is required for lobuloalveolar development and Stat5 activation during lactation. J Cell Biol 147: 77-88.

Junttila TT, Sundvall M, Lundin M, Lundin J, Tanner M, Harkonen P, Joensuu H, Isola J, Elenius K. 2005. Cleavable ErbB4 isoform in estrogen receptor-regulated growth of breast cancer cells. Cancer Res 65: 1384-1393.

Koumakpayi IH, Diallo JS, Le Page C, Lessard L, Gleave M, Begin LR, Mes-Masson AM, Saad F. 2006. Expression and nuclear localization of ErbB3 in prostate cancer. Clin Cancer Res 12: 2730-2737.

Koumakpayi IH, Le Page C, Delvoye N, Saad F, MesMasson AM. 2011. Macropinocytosis inhibitors and Arf6 regulate ErbB3 nuclear localization in prostate cancer cells. Mol Carcinog 50: 901-912.

Kraus MH, Issing W, Miki T, Popescu NC, Aaronson SA. 1989. Isolation and characterization of ERBB3, a third member of the ERBB/epidermal growth factor receptor family: Evidence for overexpression in a subset of human mammary tumors. Proc Natl Acad Sci 86: 9193-9197.

Lai C, Feng L. 2004. Implication of $\gamma$-secretase in neuregulin-induced maturation of oligodendrocytes. Biochem Biophys Res Commun 314: 535-542.

Lemmon MA, Schlessinger J. 2010. Cell signaling by receptor tyrosine kinases. Cell 141: 1117-1134.

LeRoith D, Roberts CT Jr. 2003. The insulin-like growth factor system and cancer. Cancer Lett 195: 127-137.

Li LY, Chen H, Hsieh YH, Wang YN, Chu HJ, Chen YH, Chen HY, Chien PJ, Ma HT, Tsai HC, et al. 2011. Nuclear ErbB2 enhances translation and cell growth by activating transcription of ribosomal RNA genes. Cancer Res 71 4269-4279.

Lin SY, Makino K, Xia W, Matin A, Wen Y, Kwong KY, Bourguignon L, Hung MC. 2001. Nuclear localization of EGF receptor and its potential new role as a transcription factor. Nat Cell Biol 3: 802-808.

Lo HW, Hsu SC, Ali-Seyed M, Gunduz M, Xia W, Wei Y, Bartholomeusz G, Shih JY, Hung MC. 2005. Nuclear interaction of EGFR and STAT3 in the activation of the iNOS/NO pathway. Cancer Cell 7: 575-589.

Lo HW, Cao X, Zhu H, Ali-Osman F. 2010. Cyclooxygenase2 is a novel transcriptional target of the nuclear EGFRSTAT3 and EGFRvIII-STAT3 signaling axes. Mol Cancer Res 8: $232-245$. 
S. Song et al.

Long W, Wagner KU, Lloyd KC, Binart N, Shillingford JM Hennighausen L, Jones FE. 2003. Impaired differentiation and lactational failure of Erbb4-deficient mammary glands identify ERBB4 as an obligate mediator of STAT5. Development 130: 5257-5268.

Lyu J, Yamamoto V, Lu W. 2008. Cleavage of the Wnt receptor Ryk regulates neuronal differentiation during cortical neurogenesis. Dev Cell 15: 773-780.

Myers JM, Martins GG, Ostrowski J, Stachowiak MK. 2003. Nuclear trafficking of FGFR1: A role for the transmembrane domain. J Cell Biochem 88: 1273-1291.

Ni CY, Murphy MP, Golde TE, Carpenter G. 2001. $\gamma$-Secretase cleavage and nuclear localization of ErbB-4 receptor tyrosine kinase. Science 294: 2179-2181.

Nusse R. 2005. Wnt signaling in disease and in development. Cell Res 15: 28-32.

Offterdinger M, Schofer C, Weipoltshammer K, Grunt TW. 2002. c-erbB-3: A nuclear protein in mammary epithelial cells. J Cell Biol 157: 929-939.

Peng H, Myers J, Fang X, Stachowiak EK, Maher PA, Martins GG, Popescu G, Berezney R, Stachowiak MK. 2002. Integrative nuclear FGFR1 signaling (INFS) pathway mediates activation of the tyrosine hydroxylase gene by angiotensin II, depolarization and protein kinase C. J Neurochem 81: 506-524.

Plowman GD, Culouscou JM, Whitney GS, Green JM, Carlton GW, Foy L, Neubauer MG, Shoyab M. 1993. Ligand-specific activation of HER4/p180erbB4, a fourth member of the epidermal growth factor receptor family. Proc Natl Acad Sci 90: 1746-1750.

Reichardt LF. 2006. Neurotrophin-regulated signalling pathways. Philos Trans R Soc Lond B Biol Sci 361: 1545-1564.

Rio C, Buxbaum JD, Peschon JJ, Corfas G. 2000. Tumor necrosis factor- $\alpha$-converting enzyme is required for cleavage of erbB4/HER4. J Biol Chem 275: 10379-10387.

Santos SC, Miguel C, Domingues I, Calado A, Zhu Z, Wu Y, Dias S. 2007. VEGF and VEGFR-2 (KDR) internalization is required for endothelial recovery during wound healing. Exp Cell Res 313: 1561-1574.

Sardi SP, Murtie J, Koirala S, Patten BA, Corfas G. 2006. Presenilin-dependent ErbB4 nuclear signaling regulates the timing of astrogenesis in the developing brain. Cell 127: $185-197$.

Schechter AL, Stern DF, Vaidyanathan L, Decker SJ, Drebin JA, Greene MI, Weinberg RA. 1984. The neu oncogene: An erb-B-related gene encoding a 185,000-Mr tumour antigen. Nature 312: 513-516.

Schlessinger J, Lemmon MA. 2006. Nuclear signaling by receptor tyrosine kinases: The first robin of spring. Cell 127: 45-48.

Sehat B, Tofigh A, Lin Y, Trocme E, Liljedahl U, Lagergren J, Larsson O. 2010. SUMOylation mediates the nuclear translocation and signaling of the IGF-1 receptor. Sci Signal 3: ra10.
Shi F, Telesco SE, Liu Y, Radhakrishnan R, Lemmon MA. 2010. ErbB3/HER3 intracellular domain is competent to bind ATP and catalyze autophosphorylation. Proc Natl Acad Sci 107: 7692-7697.

Stachowiak MK, Maher PA, Joy A, Mordechai E, Stachowiak EK. 1996a. Nuclear accumulation of fibroblast growth factor receptors is regulated by multiple signals in adrenal medullary cells. Mol Biol Cell 7: 1299-1317.

Stachowiak MK, Maher PA, Joy A, Mordechai E, Stachowiak EK. 1996b. Nuclear localization of functional FGF receptor 1 in human astrocytes suggests a novel mechanism for growth factor action. Brain Res Mol Brain Res 38: 161-165.

Stachowiak MK, Fang X, Myers JM, Dunham SM, Berezney R, Maher PA, Stachowiak EK. 2003. Integrative nuclear FGFR1 signaling (INFS) as a part of a universal "feed-forward-and-gate" signaling module that controls cell growth and differentiation. J Cell Biochem 90: 662691.

Sundvall M, Iljin K, Kilpinen S, Sara H, Kallioniemi OP, Elenius K. 2008. Role of ErbB4 in breast cancer. J Mammary Gland Biol Neoplasia 13: 259-268.

Tidcombe H, Jackson-Fisher A, Mathers K, Stern DF, Gassmann M, Golding JP. 2003. Neural and mammary gland defects in ErbB4 knockout mice genetically rescued from embryonic lethality. Proc Natl Acad Sci 100: 82818286.

van Amerongen R, Nusse R. 2009. Towards an integrated view of Wnt signaling in development. Development 136: 3205-3214.

Vecchi M, Baulida J, Carpenter G. 1996. Selective cleavage of the heregulin receptor ErbB-4 by protein kinase $\mathrm{C}$ activation. J Biol Chem 271: 18989-18995.

Wang SC, Lien HC, Xia W, Chen IF, Lo HW, Wang Z, AliSeyed M, Lee DF, Bartholomeusz G, Ou-Yang F, et al. 2004. Binding at and transactivation of the COX-2 promoter by nuclear tyrosine kinase receptor ErbB-2. Cancer Cell 6: 251-261.

Wang SC, Nakajima Y, Yu YL, Xia W, Chen CT, Yang CC, McIntush EW, Li LY, Hawke DH, Kobayashi R, et al. 2006. Tyrosine phosphorylation controls PCNA function through protein stability. Nat Cell Biol 8: 1359-1368.

Williams CC, Allison JG, Vidal GA, Burow ME, Beckman BS, Marrero L, Jones FE. 2004. The ERBB4/HER4 receptor tyrosine kinase regulates gene expression by functioning as a STAT5A nuclear chaperone. J Cell Biol 167: 469-478.

Zhou W, Carpenter G. 2000. Heregulin-dependent trafficking and cleavage of ErbB-4. J Biol Chem 275: $34737-$ 34743.

Zhu Y, Sullivan LL, Nair SS, Williams CC, Pandey AK, Marrero L, Vadlamudi RK, Jones FE. 2006. Coregulation of estrogen receptor by ERBB4/HER4 establishes a growth-promoting autocrine signal in breast tumor cells. Cancer Res 66: 7991-7998. 


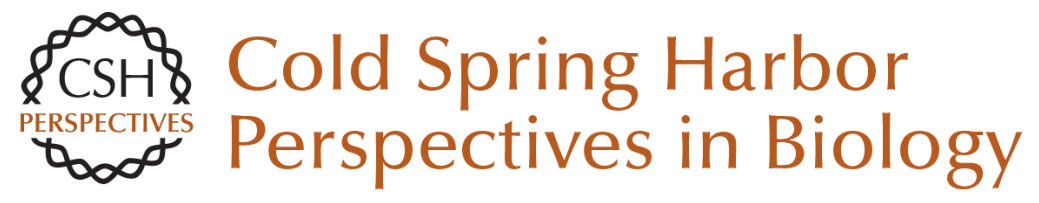

\section{Biological Function of Nuclear Receptor Tyrosine Kinase Action}

Sungmin Song, Kenneth M. Rosen and Gabriel Corfas

Cold Spring Harb Perspect Biol 2013; doi: 10.1101/cshperspect.a009001

Subject Collection Signaling by Receptor Tyrosine Kinases

CSF-1 Receptor Signaling in Myeloid Cells

E. Richard Stanley and Violeta Chitu

The EGFR Family: Not So Prototypical Receptor

Tyrosine Kinases

Mark A. Lemmon, Joseph Schlessinger and Kathryn M. Ferguson

Tie2 and Eph Receptor Tyrosine Kinase Activation and Signaling

William A. Barton, Annamarie C. Dalton, Tom C.M. Seegar, et al.

The Spatiotemporal Organization of ErbB

Receptors: Insights from Microscopy

Christopher C. Valley, Keith A. Lidke and Diane S. Lidke

Insulin Receptor Signaling in Normal and Insulin-Resistant States

Jérémie Boucher, André Kleinridders and C. Ronald Kahn

Central Role of RET in Thyroid Cancer Massimo Santoro and Francesca Carlomagno

Receptor Tyrosine Kinase-Mediated Angiogenesis Michael Jeltsch, Veli-Matti Leppänen, Pipsa Saharinen, et al.

Biology of the TAM Receptors Greg Lemke
The Genesis of Tyrosine Phosphorylation Tony Hunter

Structure-Function Relationships of ErbB RTKs in the Plasma Membrane of Living Cells

Donna J. Arndt-Jovin, Michelle G. Botelho and Thomas M. Jovin

Receptor Tyrosine Kinases: Legacy of the First

Two Decades Joseph Schlessinger

The Role of Ryk and Ror Receptor Tyrosine Kinases in Wnt Signal Transduction Jennifer Green, Roel Nusse and Renée van Amerongen

Regulation of Receptor Tyrosine Kinase Ligand Processing Colin Adrain and Matthew Freeman

Molecular Mechanisms of SH2- and PTB-Domain-Containing Proteins in Receptor Tyrosine Kinase Signaling Melany J. Wagner, Melissa M. Stacey, Bernard A. Liu, et al.

Eph Receptor Signaling and Ephrins Erika M. Lisabeth, Giulia Falivelli and Elena B. Pasquale

Effects of Membrane Trafficking on Signaling by

Receptor Tyrosine Kinases Marta Miaczynska

For additional articles in this collection, see http://cshperspectives.cshlp.org/cgi/collection/

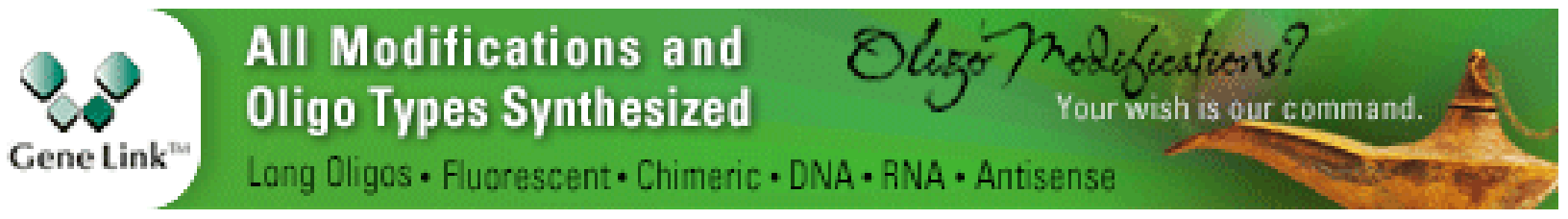


For additional articles in this collection, see http://cshperspectives.cshlp.org/cgi/collection/

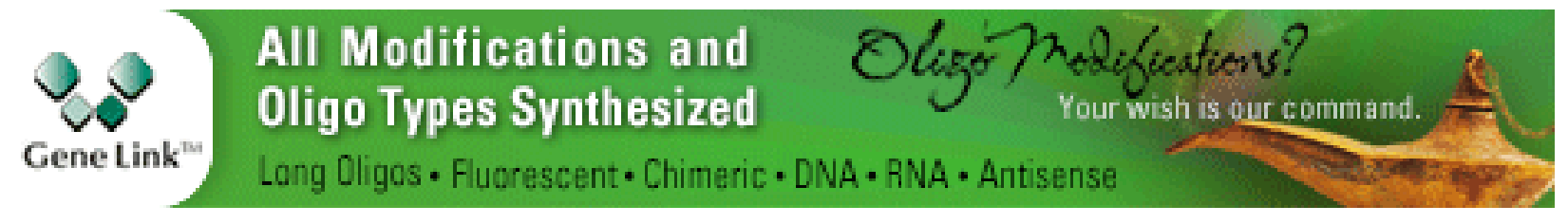

Copyright @ 2013 Cold Spring Harbor Laboratory Press; all rights reserved 